\title{
Operating with Names: Operational Definitions in the Analects and Beyond
}

\section{Dawid Rogacz ${ }^{1}$}

Accepted: 2 December 2021/ Published online: 29 January 2022

(C) The Author(s) 2022

\begin{abstract}
The philosophy of Confucius has often been accused of lacking classical definitions of its core concepts. However, as I shall argue, Confucius systematically used nonclassical definitions - to be precise, operational ones. The notion of operational definition comes from Percy Bridgman's The Logic of Modern Physics (Bridgman 1927) and means that the definiendum is defined by a set of operations that results in determining the meaning of the term in question. In the case of Confucian argumentation, operational definitions are mostly nominal and, in contrast to unambiguous methods of measurement, also context-dependent. This results in there being various yet not mutually inconsistent definitions of one term, and in "paradigmatic examples" playing a crucial role. As I show, this mode of defining things had major implications for the content of Confucius' thought. In fact, many of its forms could be traced back to other Chinese philosophers, including those of non-Confucian provenance.
\end{abstract}

Keywords Confucius · the Analects · Operationalism · Definitions · Contextualism • Chinese logic

\section{Introduction}

Chinese philosophy, and the philosophy of Confucius in particular, has quite often been criticized for lacking definitions of its core concepts. According to Max Weber, the thought of Confucius was more like the "expression of Indian chieftains rather than of rational argumentation." In Weber's eyes, because of the absence of logic and systematic speculation in China, combined with the nature of the Chinese language, "the power of logos, of defining and reasoning, was not accessible to the Chinese" (Weber 1951: 125-127). A similar opinion is also expressed by Hajime NAKAMURA: “Xunzi [荀

Dawid Rogacz

dawid.rogacz@amu.edu.pl

1 Faculty of Philosophy, Adam Mickiewicz University in Poznań, Szamarzewskiego 89C,

60-568 Poznań, Poland 
子] ... distinguished between common or general names and particular names. But he did not attain a full consciousness of 'definition' as did Aristotle.... Lack of this consciousness in a Chinese philosopher so far advanced in logical thinking is symptomatic of the general lack of consciousness of genus and differentia in the abstract among the Chinese" (Nakamura 1964: 186).

While Weber's general opinion that there is a lack of any abstract definitions in Chinese philosophy is completely misguided and racially prejudiced, Nakamura's claim may be proven true, but only insofar as classical definitions are concerned. Classical definitions are not, however, the only type of definitions. In fact, in both colloquial language and scientific practice people often use nonclassical definitions, such as, for instance, contextual, ostensive, paradigmatic, recursive, alternative, and operational ones, to name just a few.

My thesis here is that Confucius frequently used nonclassical definitions - to be precise, operational ones. The choice to focus on Confucius is motivated by the fact that he was historically the most popular target of the critics of Chinese philosophy, and as a founding figure of China's greatest philosophical tradition, criticism of Confucius' way of reasoning was almost automatically extended to the entirety of Chinese thought. In fact, the distinctiveness of Confucius' philosophy cannot be fully recognized without an insight into his method of defining things. As I shall show, the employment of operational definitions had a significant influence upon not only the form, but also the content of Confucius' thought and, to some extent, of some other Chinese thinkers, including those of non-Confucian provenance.

\section{Operational Definition}

The notion of operational definition comes from The Logic of Modern Physics (1927), written by Percy W. Bridgman (1882-1961). Bridgman was a physicist at Harvard University, whose pioneering work in the physics of high pressures was rewarded with a Nobel Prize in 1946. In his book on the philosophy of science, Bridgman attempted to define unobservable entities in terms of the physical and mental operations used to measure them. Temperature for instance, in addition to its classical definition, may be defined in terms of the characteristics ascertained by means of using a thermometer. In a similar way, Bridgman tried to redefine such fundamental physical notions as force, mass, energy, light, and field. Importantly, the vaguest and most context-dependent notions of physics, such as hardness, do not have other definitions than operational ones. ${ }^{1}$ Their definiendum is identical with a set of operations. As Bridgman puts it, "In general, we mean by any concept nothing more than a set of operations; the concept is synonymous with the corresponding set of operations" (Bridgman 1927: 5). However, as Bridgman notes in one of his later papers, since the purposes of science are restricted, the operations that can be used in assigning meanings must also be restricted. This implies the postulate that "a specification of meanings, both of isolated terms and of

\footnotetext{
${ }^{1}$ Different characteristics that are identified as hardness will be obtained if one uses different measuring instruments (hardness tester, sclerometer, rebound hammer, etc.), different measurement methods, and different tests of hardness; all of which also vary in terms of the type of materials (Mohs scale of mineral hardness, Leeb rebound hardness test, Rockwell scale, Janka hardness scale for wood, etc.).
} 
communication in toto, involves a specification of action of some sort" (Bridgman 1949: 253). The easiest way to specify such an operation in relation to physics and other experimental sciences is to give the precise circumstances which are required to lead to the desired meaning. Generally speaking, "circumstances" have to be understood as a certain type of "condition," for "to know the meaning of a term used by me it is evident, I think, that I must know the conditions under which I would use the term" (Bridgman 1938: 116).

Such an understanding of the concept of definition has some profound implications. When defining length, Bridgman observes that "to say that a certain star is $10^{5}$ light years distant is actually and conceptually an entirely different kind of thing from saying that a certain goal post is 100 meters distant" (Bridgman 1927: 17-18). Therefore, although both meters, which are measured with meter sticks, and light-years, which are measured by means of a reflected signal (a light wave) from a star, are all units of length, "length" turns out to be only a name representing a series of concepts. In fact, Bridgman admits that

In principle, the operations by which length is measured should be uniquely specified. If we have more than one set of operations, we have more than one concept, and strictly there should be a separate name to correspond to each different set of operations. (Bridgman 1927: 10)

On the other hand, Bridgman is reconciled with the fact that for practical reasons this requirement is seldom respected (Bridgman 1927: 16). This implies that, first, most operational definitions are nominal definitions. Second, concepts may be constantly redefined along with the changes within the sphere of actions, which means that operational definitions are tentative and open. Third, for these reasons, the number of operational definitions of one term is potentially infinite. Paradoxically, the last point shows the incompleteness of this type of definition. ${ }^{2}$ The potentially vast number of such definitions results from the multitude of allowed circumstances. However, if each operational definition yields a meaning that applies only in a certain situation, then it never exhausts the meaning of the term in question.

Hence, Bridgman's simple idea of defining things in terms of operations entails a series of methodological concerns. In his critical reconsideration of Bridgman's original theses, Robert H. Ennis offers a reformulation of operationalism. Ennis argues that the "spirit of operationism," by which he understands the belief in there being an important relationship between the meaning of a term and the procedures and instruments used to check whether the term applies to a given situation, can be expressed in many ways. Unfortunately, Bridgman's strict equating of the meaning of a concept with a set of operations raises serious methodological and philosophical objections. First, instead of talking about the things defined and measured, one can only relate to what the experimenter did, which does not answer the question about what the thing is. Second, no satisfactory criterion has been provided for the concept of

\footnotetext{
${ }^{2}$ Strictly speaking, the completeness of operational definitions refers to the capacity of using the same procedure over a whole range of conditions, while finiteness refers to the capacity of producing a result in a finite time. Both problems could be solved by using computational operations; see Delaney 1998: 1759.
} 
different operations. In other words, it is unclear after what change of measuring conditions (including time and space) the line between separate operations is crossed. Third, measuring instruments themselves are also subject to the changes in the environment. The reading of a thermometer, for instance, depends on exposure to radiant heat, the direction in which the thermometer is aimed, or whether a thermometer is in the sun or in the shade. This implies different concepts of "shade-temperature," "directional-radiant-temperature," and so on, which, despite Bridgman's original intentions, immensely complicates the conceptual framework of physics. Equating a phrase or sentence containing the term with a phrase or sentence about a combination of operations and observations does not solve these issues, for that would mean that a person that actually has an IQ of 120 but has not yet taken the IQ test does not (yet) have an IQ of 120 (Ennis 1964: 183-190).

The only way out of these problems is, as Ennis believes, to express the relationship between operations and meanings conditionally, and specifically by using the if-andonly-if formulation. A thing has a temperature of $60^{\circ} \mathrm{C}$ if and only if an alcohol thermometer inserted in the things reads $60^{\circ} \mathrm{C}$; a person has an IQ of 120 if and only if the Wechsler Adult Intelligence Scale administered to the person results in the score of 120. A person does have an IQ before the test (an IQ that could never be known), but cannot have an IQ of 150 if the test gives a score of 120 . The problems with criteria for different observations and the susceptibility of measuring instruments to changing environment conditions are solved by specifying the circumstances under which a defining operation will result in obtaining the meaning of the term in question or, given the lack of any particular prerequisites, at least "by adding some such phrase as "under standard conditions" (Ennis 1964: 191-192). In this manner, the general scheme of the operational definition is a reduction sentence of the following type:

$$
\forall x[\mathrm{C} x \rightarrow(\mathrm{O} x \equiv \mathrm{M} x)]
$$

when $\mathrm{C}$ - circumstances, $\mathrm{O}$ - operation, $\mathrm{M}$ - meaning.

This scheme conveys the idea that the definiendum is not identical with a set of operations, but simply defined by a set of operations that results in determining the meaning of the term in question (under the given circumstances). Due to the variety of such circumstances, operational definitions remain necessarily partial.

All these points are valid also when it comes to operational definitions of the core concepts of ethics and political philosophy, as will be clear after discussing the example of operational definitions in the Analects of Confucius. Interestingly, an application of the idea of operational definitions outside the world of physics was never ruled out by Bridgman:

Many of the questions asked about social and philosophical subjects will be found to be meaningless when examined from the point of operations. It would doubtless conduce greatly to clarity of thought if the operational mode of thinking were adopted in all fields of inquiry as well as in the physical. (Bridgman 1927: 31-32) 
What is striking about this passage is that it not only encourages the use of operational definitions in the domain of social philosophy, but also claims to have found a "criterion of demarcation" between meaningful and meaningless social concepts. Terms that cannot be defined in terms of a set of operations are supposedly meaningless. This feature is particularly important for psychologists, for "virtually every psychological method text considers operationalization, or the use of operational definitions, to be a necessity for the proper conduct of psychological research" (Slife, Wright, and Yanchar 2016: 119). Scientific psychology has to reject "all notions founded upon impossible operations," since "we can deal with the inner life only as it appears in the operations of report, verbal or otherwise" (Stevens 1935: 517, 522). The significance of operational definitions for outlining of "what we can deal with" during our interactions with other people is particularly interesting with regard to Confucius' operational definitions in the Analects.

\section{Operational definitions in the Analects}

As will be shown in a series of cases, Confucius employed operational definitions in relation to vague and context-dependent notions of the moral and political world. It is not claimed that Confucius aimed at obtaining such definitions, nor that he intended to create a settled, finite "lexicon" of ethical terms. Undoubtedly, it might be said that Confucius operated with names themselves, rather than operated on them. This notwithstanding, ignoring Confucius' constant efforts to elucidate the meaning of the crucial concepts of his philosophy runs the risk of lowering the significance of his thought. In the chapter on definitions in pre-Qin 秦 texts from the recent Dao Companion to Chinese Philosophy of Logic, Thierry Lucas emphasizes:

We should not expect that a collection of sayings like the Lunyu [論語] (Analects) contain formal definitions such as are found in mathematical or contemporary logical contexts. But there is a clear intention and numerous examples of looking for definitions of notions which became the basis of Confucianist philosophy: xiao 孝, junzi 君子, $l i$ 禮, $z h i$ 知, ren 仁,.... The context is generally given by the interaction of a disciple and the Master. The disciple is asking for the meaning of a term or the concept of a notion. (Lucas 2020: 236)

What Lucas does not point out is that the majority of these definitions are of an operational nature, ${ }^{3}$ which will now be demonstrated on the basis of the selected passages of the Analects.

Most readers of the Analects are puzzled by Confucius' silence with regard to defining the crucial Confucian virtue, benevolence ren 仁. In fact, it is explicitly stated that Confucius seldom spoke about ren (Analects 9.1). Consider then Analects 12.2, where Confucius' answer to the question about ren starts with the words: "It is, when

\footnotetext{
${ }^{3}$ Some of his comments on Confucius' definitions, however, are strikingly close to the approach proposed here, although none of them identifies those definitions as operational ones. Compare with his note on Analects 2.13: "It is clear that the point of the definition is to give an explanation of how gentlemen behave and implicitly to make the recommendation to behave in the way described" (Lucas 2020: 238).
} 
you go abroad, to behave toward everyone as if you were receiving a great guest."4 Interestingly, this answer perfectly fits the structure of operational definition, namely: "In the circumstances of being abroad, if you behave toward everyone as if you were receiving a great guest, then it means you have benevolence." It is clear that the meaning of ren is obtained through a set of operations made in certain circumstances. As a result, the definition consists of conditionals instead of existential statements and thereby fully complies with the reduction sentence of type: $\forall \mathrm{x}[\mathrm{Cx} \rightarrow(\mathrm{Ox} \equiv \mathrm{Mx})]$. Confucius' answer, however, is not complete, for the definition continues: "Not to do to others as you do not wish done to yourself; to have no complaints in your country and your family." In this case, no particular circumstances are mentioned. Instead, Confucius seems to presuppose the validity of his definition in all situations under standard conditions, to use Ennis' formulation. Even then, however, the operational structure of his definition is still evident: you are benevolent if and only if you do not do to others what you do not want to be done to yourself and if you have no complaints in your country and family. No classical definition is given.

Another operational definition of ren is proposed in Analects 17.6: “ $\mathrm{Zi}$ Zhang 子張 asked Confucius about benevolence. Confucius said, 'To be able to practice five virtues $^{5}$ everywhere under Heaven constitutes benevolence'." Adjusted to the form of the reductive sentence, the definition reads as follows: "Everywhere you go, if you practice five virtues, then it means you are benevolent." Certainly, in the case of this definition, the scope of circumstances required to pursue the defining operation is rather broad, which - if it were not for its conditional form that refers to particular actionsdraws near a classical definition of ren (ren as a "constant practice of five virtues"). It seems that with regard to ren, which was considered the most fundamental and universal among Confucian virtues, Confucius tried to define it in a way applicable to various possible situations, or in other words, to produce a "unifying thread" running along the indicated Way (cf. Lippiello 2010: 82-83, 94-97).

In most cases, however, the circumstances are delineated in quite a detailed manner, inviting us to imagine the given situation (to make a "thought experiment," so to speak), in other words, to ask ourselves about our possible reaction in that concrete predicament:

YAN Yuan [顏淵] asked about benevolence. The Master said, "To subdue one's self and return to propriety, is benevolence. If a man can for one day subdue himself and return to propriety, all under Heaven [Tianxia 天下] will ascribe benevolence to him." (Analects 12.1)

Hence, the operational definition of ren in Analects 12.1 goes as follows: "In the situation of subduing one's emotions for one day, if you can return to ritual propriety, then it means you are benevolent." Another hypothetical situation is portrayed in Confucius' answer to the provocative question of Zai Wo 宰我 in Analects 6.26, which could be translated into the following definition: "If it should happen that you hear

\footnotetext{
${ }^{4}$ All translations to the Chinese texts cited in this article are mine. References are made to the book and page numbers from the editions on which the English translations are based, except for conventional references as to the Analects and Mencius (listed under Lunyu and Mengzi, respectively, in References).

${ }^{5}$ Namely benevolence $(r e n)$, righteousness ( $y i$ 義), propriety ( $l i$ 禮), wisdom ( $z h i$ 智), and trustworthiness ( $x i n$ 信).
} 
there is a man in the well, if you go to the well but do not go down into it, and are not being fooled, then it means you are a benevolent man."

Similar definitions are formulated with regard to other virtues and core concepts of Confucius' thought. Take the virtue of filial piety xiao 孝 as an example. The famous passage in Analects 1.11 reads: "After father is dead, look at his conduct. If for three years he does not change the way of his father, he may be called filial." The conditional nature of this sentence allows us to rephrase it in the form of operational definition: "In the circumstances of your father having died, if you adhere to his ways for the next three years, then it means you are filial." More obscure replies to questions considering filial piety may be also explicated in such a way. Consider Analects 2.6: "Meng Wubo 孟武伯 asked what filial piety was. The Master said: When parents are upset only about their falling ill." In this case, it would be desirable to supplement the definition with additional information, for instance, "When your parents are alive, if you do not upset them [so that the only reason for their sadness is not dependent on you, e.g., it is caused by their sickness], then it means you show filial devotion." Even then, the basic structure of the operational definition does not necessarily require such an addition.

Operational definitions are quite often involved in illuminating the meaning of the concepts that play a key role in Confucius' philosophy of education and cultivation. Analects 2.11, the passage which is also crucial for understanding Confucius' attitude toward history, reads: "If a man keeps refreshing his knowledge of the ancient standards so as to know the new, he is able to be a teacher." The operational form of this declaration could be encapsulated as follows: "When refreshing the knowledge of the ancient standards, if you do so in order to know the new, then it means you are able to be a teacher." Analects 1.14 characterizes the exemplary person as one who "does not seek to satisfy appetite for food in an excessive manner, nor in his habitation does he seek excessive comfort," so that "such a person may be said to love to learn," thereby offering an operational definition of the passion for learning: "When eating/ living, if you do not seek to satisfy appetite/facilitations, then it means you are a lover of learning.” Even ming 明 (intelligence) is defined in an operational manner:

$\mathrm{Zi}$ Zhang asked what constituted intelligence. The Master said, "He who does not base his actions on slanders that gradually seep into the mind, or accusations that accumulate like dirt on the skin, may be called intelligent (ming)." (Analects 12.6)

The definition of intelligence proposed by Confucius is, therefore, that "In the circumstances of facing with slanders or hasty accusations, if you do not base your actions upon them, then it means you are intelligent." In Analects 14.42, the definition of the exemplary person cross-refers to the concept of self-cultivation:

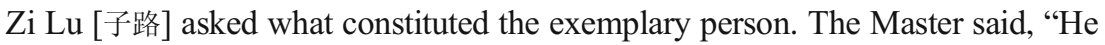
who cultivates himself with reverence." "Is that all?" asked $\mathrm{Zi} \mathrm{Lu}$. "He who cultivates himself so as to put other people at ease." "And is that all?" asked Zi $\mathrm{Lu}$. "He who cultivates himself so as to give rest to all the people. This is what Yao [堯] and Shun [舜] were concerned about!” (Analects 14.42)

The operational definition expressed in this passage goes as follows: "When cultivating yourself, if you are able to do it with reverence so that eventually you bring peace also 
to all other people [and not only to yourself], then you are an exemplary person." This definition is particularly intriguing, because it directly shows its partial nature: if $\mathrm{Zi} \mathrm{Lu}$ had not persistently reasked the question, we would have only received the first answer. Even then, we are still not sure whether there was something else that Confucius could have added on the matter, either on another occasion or to another person. Sensing the impatience of the disciples, Confucius refers to the example of Yao and Shun as a resource in which one can find more answers to one's burning questions. (I will discuss the function of such examples in the later part of the essay.)

Finally, the core concepts of Confucius' political philosophy are also subject to operational defining, such as in Analects 12.14 when Confucius' answer to Zi Zhang's question about governing (zheng 政) starts with the words: "The art of governing is to occupy the position without wearying, and to practice it dutifully," which articulate the following idea: "Should you be appointed an official position, if you occupy it without wearying and practice it dutifully, then it means you are prepared for governing." Note that Confucius' famous "when the sovereign is the sovereign, the minister is minister, the father is father, and the son is son” (jun jun, chen chen, fu fu, zi zi 君君臣臣父父子子) comes as a direct response to the question concerning governance posed by the Duke Jing 景 of Qi 齊 himself (Analects 12.11).

These are some of the operational definitions of the core concepts of Confucius' philosophy, which are definitely not exhaustive, but already prove the importance of highlighting this way of defining things for our better understanding of the Analects, all the more so that quite often definitions such as these come as an answer to the questions formulated by Confucius' disciples.

Importantly, the above-discussed instances also exemplify the features of operational definitions that are typical of Confucianism. First, Confucian operational definitions are usually not real definitions (A is B), but rather nominal ones (A is called B), ${ }^{6}$ which is evident from the use of the phrase kewei 可謂 (could be named). This is all the more interesting since operational definitions are usually classified under partial definitions, ${ }^{7}$ for it is practically impossible to find only one unambiguous and definitive action that leads to obtaining the meaning in question. This feature is here stressed by the modal verb ke 可. Accordingly, strong equations, expressed with the construction “... zhe 者, ... ye 也," are usually avoided in Confucius' definiendum. Second, although the questions posed by Confucius' disciples could be easily translated into those concerning abstract nouns ("benevolence," "filial piety," "intelligence," "governing"), the answer always transforms them into the predicates, and more precisely-into the properties (or "proprieties") of persons. In the above-quoted passage from Analects 12.1, the nominal and the "personalist" aspect of Confucian operational definitions is apparent: when asked about benevolence, Confucius describes the set of actions that have to be performed in order to be recognized as benevolent by all people. This is not, however, a theoretical inconsequence. In relation to the world of science there may be some relatively unambiguous and definitely impersonal methods of measurement, but with regard to the social world, the operations that lead to defining ethical terms cannot be understood separately from the person whose behavior is to be morally judged. This

\footnotetext{
${ }^{6}$ On the difference between real and nominal definitions, see Cargile 1991.

${ }^{7}$ Partial definition does not exhaust its definiens. This means that if A is (B \& C \& D), partial definitions of A are, respectively: $\mathrm{A}$ is $\mathrm{B}, \mathrm{A}$ is $\mathrm{C}$, and $\mathrm{A}$ is $\mathrm{D}$.
} 
is strictly connected with the third distinctive feature of Confucian operational definitions, namely that they are strongly context-dependent. This results in having various yet not mutually inconsistent definitions of one term, often depending on the situation or disciple to whom the definition is addressed. In other words, the condition for the proper part of the definition ("in the circumstances of...") is taken seriously here, even at the price of losing meaning equivalence, supposing that it has ever been an option. Contextualist blurring the lines between seemingly clear-cut definitions of ethical terms does not, however, lead to any sort of relativism, and while different definitions of one term taken together do seem diverse, they are never mutually inconsistent. From this point of view, WANG Yangming's 王陽明 celebrated idea of “unity of knowledge and action" (zhi-xing heyi 知行合一) (Chuanxilu 2: 41-43) seems to be a continuation of and epistemological grounding for Confucius' way of defining things; but then the question arises as to whether Confucius himself was aware of the mode of defining he was using.

Given the current received text of the Analects, and given the fact that an explicit elaboration on argumentative strategies was the work of the later generations of Confucians, the answer is rather negative. However, the gradual nature of this process requires us to assign Confucius his rightful place in this philosophical development. Although Confucius' acceptance of operational definitions may not be open, he directly supported the theoretical framework that is conducive to this type of definition. One of the main instances of such an attitude is to be found in Analects 2.13, which is, incidentally, expressed within the operational definition of the exemplary person (junzi 君子): “ $\mathrm{Zi}$ Gong [子貢] asked what constituted the exemplary person. The Master said, 'He firstly puts his words into practice and only then does he follow them' (xian xing qi yan er hou cong zhi 先行其言而後從之).” Although this quote does not recommend the operational way of defining things, it says that only beliefs that have been checked against practical results can be accepted and promoted, and it is difficult to find a type of definition that would be better suited to go through this test than the operational ones, all the more so as they stipulate particular circumstances under which the action should be performed. Another interesting insight is brought by Analects 3.11:

Someone asked about the meaning of the $d i$ [禘] sacrifice. The Master said, "I do not know. One who knew its meaning would find it as easy to govern the world as to look on this" - and he pointed to his palm. (Analects 3.11)

The question directly concerns the explicit meaning (explanation) (shuo 說) of the $d i$ sacrifice, yet Confucius responds that he himself does not know ( $z h i$ 知) it, and what is more- he does not refer us to someone who already knows it, but points out that the knowledge of the meaning of this sacrifice would come to those who would govern the kingdom with ease. It is clear why Confucius does not know it: he is not the ruler of the state, while the knowledge of the meaning in question could only emerge as a result of this type of action. Since knowledge is gained by actions, actions themselves should also be aimed at gaining knowledge, and not limited to unreflective or habitual doings: "The Master said, 'There may be those who act without knowing why. I am not like them"" (Analects 7.28). The relation between knowledge and actions is bilateral, which requires the ability of knowledge to be put into practice and, accordingly, such a form of definition that enables us to test definitions in various circumstances. Opposing 
“those who act without knowing why" (buzhi er zuo zhi zhe 不知而作之者), Confucius at the same time stands against reducing knowledge to some form of practice, which excludes an instrumentalist (Deweyan) interpretation of Confucius' use of operational definitions. ${ }^{8}$ The rejection of such instrumentalism is precisely the reason why Confucius needs definitions in the first place.

A good example of how to approach Confucian argumentation from the viewpoint of pragmatism was given by Yang XIAO, in the article under the meaningful title "How Confucius Does Things with Words." Xiao argues that Confucius' utterances are neither plain statements, nor are they-due to the crucial role of the intentions and purposes of the speaker-forms of merely adaptive and pre-theoretical behavior. As Xiao writes,

The paradigm that Confucius represents regards an utterance always as an action, and it takes into account multiple pragmatic dimensions of the total speech act. Besides the literal meaning, the "total speech act" approach takes into account what the speaker intends to do with the utterance (the force), whom the speaker is addressing (the audience), as well as the ends that the speaker intends to achieve (the purpose). (Xiao 2007: 498)

Xiao's approach is different from mine, not only due to the fact that Xiao does not use the notion of definition, but mostly in the different targets of our argumentation. Whereas Xiao stresses that Confucius' sentences are only part of a larger, pragmatic "environment," which results in focusing on the actions constituted by the utterances (such as "telling a joke" or "expressing a wish"), I argue that the very form of the defining sentences is of an operational nature even when we abstract from everything that lies outside of the utterances themselves. This difference, however, makes our viewpoint completely complementary. In fact, it is difficult to find a type of definition that would be better prepared to perform its pragmatic function than one that is based on the idea of defining meanings in terms of sets of operations.

\section{The Implications of Confucius' Use of Operational Definitions}

Confucius' employment of the method (or tool) of defining concepts operationally has some important philosophical implications. This does not mean that the implications discussed below are totally and exclusively derivable from the formal structure of Confucius' discourse itself, and not its content, but rather that some part of this content, along with some of its direct implications, may be seen as stemming from the premises lying behind operational definitions, some of which were pointed out by Bridgman and Ennis.

The first implication is connected with the fact that operational definitions for ethical terms are seldom recursive. There are, of course, some examples of such finite lists of

\footnotetext{
${ }^{8}$ For Dewey, to have an idea of a hammer is to be able to use it to drive a nail. "Ideas" are nothing but mental predictions of what might happen, which are then tested against reality and become instruments of adaptation to the environment (see Dewey 1910). Importantly, Confucius would also have opposed instrumentalism on ethical grounds, due to Dewey's denial of the intrinsic value of virtues and the reduction of ideas to the tools of survival that ultimately serve only one's profit.
} 
operations, as in Analects 17.6 where, when asked about the meaning of ren, Confucius answers that it is gained through practicing five virtues, and then enumerates them. Each of these virtues, however, has to be defined operationally (one of them is xin 信, "reliability," which is highly contextual). This means that in order to not be petrified of having too many proper operations to perform, some exemplary models of behavior have to be put forward, which then are to be followed in one's practical life. This explains the number of technical terms denoting "following" in Confucian writings, and the frequency of their use, such as cong 從 (follow), shun 順 (conform with), yin 因 (adapt to), sui 隨 (go along with), zun 遵 (respect), and xun 循 (abide by), to name just a few. Importantly, the choice of models that are to be followed does not merely result from some sort of attachment to cultural heritage, for Confucius stresses that there is always a basis ( $s h i$ 試) for his condemning or praising certain attitudes (Analects 15.25).

Nor does Confucius call for a blind obedience, for, as TAN Sor-hoon convincingly shows, his strategy is authoritative rather than authoritarian, in that it is based on voluntary compliance with moral authority rather than coercion and force (Tan 2010), as is explicitly stated by Confucius in Analects 2.3. In this way, Confucius' method strikingly resembles what Wittgenstein called "paradigmatic examples.",

The role of examples in Confucius' argumentation did not go unrecognized. As early as 1969, Antonio Cua pointed out that the Confucian method, in contrast to the Socratic one, is based not on general concepts, but on specific examples (Cua 1969: 29-30). Amy Olberding offers a comprehensive interpretation of the Analects through the prism of exemplarism, attempting to "discern a governing logic that renders the Analects' compelling moral sensibility intelligible as moral theory" (Olberding 2012: 1). In her opinion, exemplarism provides a good explanation of Confucius' "silences" about human nature and virtues, with ren on top, because it focuses on how emulating paradigmatic figures leads people to be moral, and thereby treats examples not as illustrations of abstract concepts, but necessary and indispensable instances that are pretheoretically identified by all people (Olberding 2012: 11, 43-53). The main problem with this approach and the reason why it is still different from the view stemming from reading the Analects with the idea of operational definitions is diagnosed by TAN Sorhoon:

Olberding's impression is that the Analects does not achieve a "stable, settled account of ren" but argues that this matters less for an exemplarist reading in which it becomes a problem "not in discovering something we do not know but in explaining something we do"... However, the admission of the lack of an authoritative account may undermine readers' confidence in reading the text as moral theory. (Tan 2013: 262)

\footnotetext{
${ }^{9}$ In Wittgenstein's eyes, certain language-games become paradigmatic examples of a group that is related by family resemblance. The voluntariness of the process of following paradigmatic examples is stressed in $\S 208$ of Philosophical Investigations: "But if a person has not yet got the concepts, I shall teach him to use the words by means of examples and by practice.-And when I do this I do not communicate less to him than I know myself. In the course of this teaching I shall show him the same colours, the same lengths, the same shapes, I shall make him find them and produce them, and so on.... I do it, he does it after me; and I influence him by expressions of agreement, rejection, expectation, encouragement. I let him go his way, or hold him back; and so on" (Wittgenstein 1969: 83).
} 
Understanding the Analects as containing examples rather than concepts inevitably reduces the text to a moral manual rather than expounding on its moral theory. Both Cua and Olberding seem to be trapped by a false dichotomy of "abstract" and "general" concepts or "pre-theoretical" and "specific" examples, whereas it is Confucius' defining concepts in terms of the operations required to obtain their meaning that necessitates the frequent following of exemplary figures in life practice.

The most popular among the paradigmatic examples of Confucian philosophy are former great rulers, such as Yao, Shun or the founders of the Zhou 周 dynasty, who performed the operation that defines a given ethical notion in question perfectly. The examples of Yao and Shun in particular are treated by Confucius in an almost formal and definitely rhetorical way. The conduct of Shun, for instance, is many times put forward as an instance of perfect governance, in response to the question concerning its definition (Analects 8.20, 12.2, 15.5). Quite tellingly, Confucius says that Shun's virtue was so vast that people could not find a name (ming 名) for it (Analects 8.19). This is, again, understandable in light of the fact that only one who could perfectly follow Shun's conduct would be able to grasp the meaning of virtue as he did. ${ }^{10}$

In a broader sense, paradigm-oriented operational definitions lead to the specific interest in history and usage of historical figures within argumentation. This implies the moral use of the past, which became a constitutive feature of Confucius' historical thinking. Confucius' postulates of "warming up the old in order to know the present" (Analects 2.8) and "transmitting instead of creating, by trusting in and loving the past" (Analects 7.1) express this idea, which was later explicitly enunciated by Xunzi: "We observe past events in order to take precautions against them. Order, anarchy, right and wrong can be recognized in them" (Xunzi 25: 468). Since apart from ethical notions, operational definitions very often explained the meaning of political terms, this function translates into the political aim of historiography. Commenting on Sima Guang's 司 馬光 Zizhi Tongjian 資治通鑑 (Comprehensive Mirror for the Aid in Government), Robert Hartwell argues that moral didacticism, in which moral lessons are taken up by individuals, has to be distinguished from what he calls "historical analogism," in which history is said to provide the tools for the assessment of social and political institutions (Hartwell 1971: 694). Both ways of reading history result, though, from the involvement of historical paradigmatic examples in the operational defining of core philosophical concepts. It is therefore not surprising that the Chinese tradition has credited Confucius with the merit of authoring or at least editing the Spring and Autumn Annals (Chunqiu 春秋), believing that the mentioning, omitting and finally the narrative shape of given historical events was motivated by his desire to put forward examples of proper or improper conduct (in both moral and ritual terms). In fact, throughout Chinese history Chunqiu was quite often recognized as the most important work of Confucius, which seems odd to its contemporary readers if it is not appreciated that its paradigms and paragons of conduct (or misconduct) created a ready-made, comprehensive moral guidebook, in contrast to the still rather general and often indirect operational definitions of the Analects. Various classes of the explanatory meaning of historical examples can be easily recognized within the Chunqiu narrative (see Rogacz 2018). As a result, the intellectual effort of living Confucians has shifted from (always

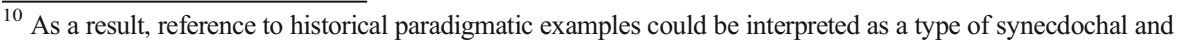
integrative historical discourse in the sense given by Hayden White (Rogacz 2017).
} 
contextual and inevitably partial) operational definitions into the hermeneuto-technical recognition of instances of moral/proper/just conduct within practical and everchanging social life that resemble given paradigmatic examples. This may have led to the fact that the initial interest in defining things, which was at the center of philosophical debates in the Warring States period, gradually faded away after the "hermeneutical turn" of the Han 漢 exegesis of the Chunqiu, thereby creating the impression that the Confucians, or even the Chinese, are generally not interested in definitions.

Last but not least, one of the most important consequences of the operational defining of core philosophical concepts is that everything that cannot be defined in terms of the effect of manageable operations lies beyond the scope of philosophical interest: whereof one cannot do, thereof one must be silent. This finds its manifestation in Confucius' idea of destiny (ming 命). "Death and life: this is ming," he says (Analects 12.5); people cannot change ming if it prevents them from putting Dao 道 into practice (Analects 14.36). At first glance, this may look like fatalism, and the Mohists certainly saw it that way, but the interpreters of this aspect of the Confucian philosophy have no doubts: as CHEN Ning shows, the idea of ming rather demarcates what is dependent on, and independent of, human activity (Chen 1997: 330, 343), being "the expression of a mature and realistic assessment of the limits of human power" (Slingerland 1996: 577). This also explains why Confucius refused to define such things as miracles, afterlife, ghosts, or spirits (Analects 7.21).

Both Socrates and Confucius, great founders of even greater philosophical traditions, put a lot of effort into defining concepts. Socrates based his teaching on classical definitions, Confucius on operational ones. Socratic classical definition, starting from recognizing the genus proximum to which a given particular thing belongs, and proceeding to finding a distinctive yet abstract differentia specifica, clearly favors defining notions in terms of their essences. Confucius' definitions, in turn, "are not used to analyze in a Socratic way the 'essence' of a notion, but they are intended to answer in a generally concrete way ethical and political problems" (Lucas 2020: 237; italics mine).

These essences, seemingly able to exist as some sort of entities detached from their "transmitters" ("justice" outside of "just" people) become known as Platonic ideas, and even Aristotle still used the term $i \delta \varepsilon \dot{\varepsilon} \alpha$ for what is usually known as "forms" or "essences." This implied the particular preference of metaphysics, which is different from Confucian thought, to which the Platonic vision of ideas and the view of metaphysics built upon it seem totally redundant and unnecessary, if not completely alien. ${ }^{11}$ On the other hand, it is Socrates who struggles with defining actions, arguing that since a craftsman cannot tell him what the craft in general is, he cannot be a craftsman. This strategy often amuses the readers of Socrates' disquisitions (and it definitely aggravated the Athenians), but it does not stem from the mere ignorance of the existence of knowledge-how, rather from a struggle to fit context-dependent actions into the Procrustean bed of classical definitions. When the practical and visible world does not fit the ideal scheme, which happens all the time, the only rational solution is skepticism regarding what is visible. This being the case, a Greek philosopher risks

\footnotetext{
${ }^{11}$ The contrary view, however, has been long popular due to FENG Youlan's 馮友蘭 interpretation of Chinese philosophy.
} 
losing much of his initial certainty: under the pressure of such skepticism his edifice of knowledge would imminently fall apart. That is why Socrates ultimately "knows that he knows nothing." Confucius is not that radical, giving us slightly different (and again, operational!) definition of knowledge: "To know what is known and to not know what is unknown, this is knowledge" (Analects 2.17). Such a notion of knowledge crossrefers to the concept of ming, namely to what lies inside and outside the real possibilities of getting to know things. The sphere of what is knowable is modest, but unlike Socrates, Confucius does not think that meanings resulting from human actions are undefinable. Socrates is trapped by his absolutism, which forbids him to treat abstract essences on a par with contextualized doing and personal traits. On the other hand, did Confucius restrain from writing because the true meaning of the concepts important for one's life could be gained only through practice? This is what we do not know. In any case, the reading of Confucius through the prism of his employment of operational definitions undoubtedly sheds a new light on the distinctive nature of his thought and brings new impulses for comparative philosophy.

\section{Postscriptum: Beyond the Analects}

Although operational definitions are preferred by Confucius as the most appropriate type of definitions, their usage is by no means restricted exclusively to the Analects, as it can be traced both in the later development of Confucianism, as well as in texts outside Confucianism. In fact, indicating instances of the "later life" of operational definitions in Chinese philosophy only strengthens the validity of extracting them from within the text of the Analects. Since it is hard to treat the Analects as an isolated text that has nothing to do with argumentative strategies employed in other philosophical texts of the Warring States period, it is all the more difficult to maintain that operational definitions must have occurred only in the text of the Analects.

From this viewpoint, Mencius' third argument against Gaozi 告子 is based on uncloaking the usefulness of Gaozi's strong equation (shengzhi wei xing 生之謂性, "nature is what is born") in the face of the contextual differentiation of the meaning (Mengzi 6A3). It contrasts with Mencius' own belief, that only by means of exhausting one's heart-mind could one gain knowledge of human nature (Mengzi 7A1), which leads rather to an operational definition. Also the key concepts of ren and yi are defined in that way: "All human beings have something which they cannot bear. Extending this feeling to reach to what they can bear is benevolence. All human beings have something which they will not do. Extending this attitude to reach to that which they will do is rightness" (Mengzi 7b31). Asked about the meaning of "good" and "trust," Mencius gives a series of operational (and nominal) definitions ending with a definition of the sage: 'One who takes our liking is called 'good.' Having goodness within oneself is what is called 'trustworthy.' When it is filled up within oneself, one is called 'beautiful.' When it is filled up and brightly displayed, one is called 'great.' When one is great and exercises a transforming influence, one is called a 'sage'" (Mengzi 7B25). Operational definitions are also contained in the Xunzi, with the definitions of politics (zheng 政) and sovereign (renjun 人君) on top (Xunzi 9: 148, 12: 232). However, its description, along with the discussion of their relation to Xunzi's sophisticated philosophy of language, goes far beyond the limits of this essay. 
Operational definitions are also to be found outside of Confucianism. How else should we interpret the function of Zhuangzi's 莊子 parables which illustrate the patterns of operations that result in understanding the meaning of Dao or, as in the case of the Cook Ding 丁, of the art of “nourishing life" (yangsheng 養生) (Zhuangzi 3: 117-119)? Is it not through walking along the same river that enables Zhuangzi to know (zhi) the happiness of the fish (Zhuangzi 17: 606-607)?

The Explanations of the Mohist Canons, in addition to classical definitions, often use operational ones, usually along with analogy. This regards both epistemological concepts, such as “thinking” ( $l \ddot{u}$ 慮): “Thinking: by means of one's intelligence one seeks something, but does not necessarily find it; like peering" (Mozi 10: 333); and ethical ones, such as "rightness" ( $y i$ 義): “In intent, one takes the whole world as one's field; in ability, one is able to benefit it, although not necessarily employed" (Mozi 10: 334), just to mention these two representative examples.

Finite definitive enumeration of the operational definitions employed by Chinese philosophers of the classical era is not, however, the aim of this essay. By showing that operational definitions were used elsewhere, and not just in the Analects, it shows, though, that the task of penetrating the works of Chinese philosophers in search of operational definitions is completely manageable, and definitely not for the purpose of showing off scholarly erudition, but rather in the hope that explicating the Chinese way of defining in terms of operational definitions could at least specify the meaning of the defined concepts (for instance by finding out the implicit circumstances of a given operation), and solve some problems with their understanding.

\section{Conclusion}

The study argues that despite the historical criticism of Confucius' philosophy for its lack of classical definitions, the Analects systematically employ operational definitions. The method of operational definition comes from Percy Bridgman's The Logic of Modern Physics (1927) and was later developed by many psychologists and education theorists, in particular Robert H. Ennis. The idea of operational definition means that the definiendum is defined by a set of operations that results in determining the meaning of the term in question. As is shown in a series of cases, Confucius employed operational definitions in relation to core concepts of his thought, including the notions of benevolence, filial piety, cultivation, and governing, and supported the theoretical framework conducive to this argumentative strategy. In the case of Confucian argumentation, operational definitions are mostly nominal, context-dependent and "personalist." This results in having various yet not mutually inconsistent definitions of one term, and in "paradigmatic examples" having a crucial role. This, in turn, translates into Confucius' interest in the moral and political use of history, at the same time leading to a turning away from defining the meanings of things that cannot be affected by human action, which brings about interesting differences between the nature and use of definitions in Socrates and Confucius. Finally, by showing that operational definitions were also used outside of the Analects, the study concludes that the explication and extraction of operational definitions is a promising method for examining Chinese philosophical texts. 
Acknowledgment This work was supported by Narodowe Centrum Nauki (National Science Centre) in Poland, grant no. 2019/33/B/HS1/00244.

Open Access This article is licensed under a Creative Commons Attribution 4.0 International License, which permits use, sharing, adaptation, distribution and reproduction in any medium or format, as long as you give appropriate credit to the original author(s) and the source, provide a link to the Creative Commons licence, and indicate if changes were made. The images or other third party material in this article are included in the article's Creative Commons licence, unless indicated otherwise in a credit line to the material. If material is not included in the article's Creative Commons licence and your intended use is not permitted by statutory regulation or exceeds the permitted use, you will need to obtain permission directly from the copyright holder. To view a copy of this licence, visit http://creativecommons.org/licenses/by/4.0/.

\section{References}

Bridgman, Percy W. 1927. The Logic of Modern Physics. New York: The Macmillan Company. 1938. "Operational Analysis." Philosophy of Science 5: 114-131. 1949. "The Operational Aspect of Meaning." Synthese 8.1: 251-259.

Cargile, James. 1991. "Real and Nominal Definitions." In Definitions and Definability: Philosophical Perspectives, edited by James H. Fetzer, David Shatz, and George N. Schlesinger. Synthese Library vol. 216. Dordrecht: Springer.

Chen, Ning. 1997. “Confucius' View of Fate (Ming).” Journal of Chinese Philosophy 24.3: 323-359.

Chuanxilu 傳習錄. 1992. In Complete Works of WANG Yangming 王陽明全集, vol. 1, edited by Wu Guang 吳光, QIAN Ming 錢明, DONG Ping 董平, YAO Yanfu 姚延福. Shanghai 上海: Shanghai Guji Chubanshe 上海古籍 出版社.

Cua, Antonio S. 1969. "The Logic of Confucian Dialogues." In Studies in Philosophy and the History of Philosophy, vol. 4, edited by John Ryan. Washington, DC: Catholic University of America Press.

Delaney, William. 1998. "Limitation of Operational Definitions." International Journal of Theoretical Physics 38.6: $1757-1762$.

Dewey, John. 1910. The Influence of Darwin on Philosophy and Other Essays in Contemporary Thought. New York: Henry Holt and Company.

Ennis, Robert H. 1964. "Operational Definitions.” American Educational Research Journal 1.3: 183-201.

Hartwell, Robert. 1971. "Historical Analogism, Public Policy, and Social Science in Eleventh- and TwelfthCentury China." The American Historical Review 76.3: 690-727.

Lippiello, Tiziana. 2010. "A Confucian Adage for Life: Empathy (Shu) in the Analects." In Light a Candle: Encounters and Friendship with China. Festschrift in Honour of Angelo Lazzarotto P.I.M.E., edited by Roman Malek S.V.D. and Gianni Criveller. Sankt Augustin: Monumenta Serica.

Lucas, Thierry. 2020. "Definitions in Pre-Qin Texts." In Dao Companion to Chinese Philosophy of Logic, edited by Fung Yiu-ming. Cham: Springer.

Lunyu 論語. 1999. In Commentaries and Explanations to the Thirteen Classics 十三經註疏, vol. 10, edited by Li Xueqin 李學勤. Beijing 北京: Beijing Daxue Chubanshe 北京大學出版社.

Mengzi 孟子. 1999. In Commentaries and Explanations to the Thirteen Classics 十三經註疏, vol. 11, edited by Li Xueqin 李學勤. Beijing 北京: Beijing Daxue Chubanshe北京大學出版社.

Mozi Jiangu 墨子閒詁. 2009. Edited by SuN Yirang 孫詒讓. Beijing 北京: Zhonghua Shuju 中華書局.

Nakamura, Hajime. 1964. Ways of Thinking of Eastern Peoples: India-China-Tibet-Japan. Honolulu: The University of Hawai'i Press.

Olberding, Amy. 2012. Moral Exemplars in the Analects: The Good Person Is That. New York: Routledge.

Rogacz, Dawid. 2017. "The Motif of Legendary Emperors Yao and Shun in Ancient Chinese Literature." In Rethinking Orient: In Search of Sources and Inspirations, edited by Adam Bednarczyk, Magdalena Kubarek, and Maciej Szatkowski. Warsaw: Peter Lang.

2018. "Spring and Autumn Annals as Narrative Explanation". In Towards a Revival of Analytical Philosophy of History: Around Paul A. Roth's Vision of Historical Sciences, edited by Krzysztof Brzechczyn. Leiden-Boston: Brill.

Slife, Brent D., Casey D. Wright, and Stephen C. Yanchar. 2016. "Using Operational Definitions in Research: A Best-Practice Approach.” The Journal of Mind and Behavior 37.2: 119-140. 
Slingerland, Ted. 1996. "The Conception of Ming in Early Confucian Thought." Philosophy East and West 46.4: $567-581$.

Stevens, S. S. 1935. "The Operational Definition of Psychological Concepts." Psychological Review 42.6: 517-527.

Tan, Sor-hoon. 2010. “Authoritative Master Kong (Confucius) in an Authoritarian Age.” Dao 9.2: 137-149. . 2013. "Moral Exemplars in the Analects: The Good Person Is That. New York: Routledge, 2012, x+ 232 pages." Dao 12.2: 261-265.

Xiao, Yang. 2007. "How Confucius Does Things with Words: Two Hermeneutic Paradigms in the Analects and Its Exegeses." The Journal of Asian Studies 66.2: 497-532.

Xunzi Jijie 荀子集解. 1988. Edited by WANG Xianqian 王先謙. Beijing 北京: Zhonghua Shuju 中華書局.

Weber, Max. 1951. The Religion of China: Confucianism and Taoism. Trans. by Hans Gerth. Glencoe, IL: The Free Press.

Wittgenstein, Ludwig. 1969. Philosophical Investigations. Trans. by G. E. M. Anscombe. 3rd ed. Oxford: Basil Blackwell.

Zhuangzi Jishi 莊子集釋. 1961. Edited by Guo Qingfan 郭慶翻. Beijing 北京: Zhonghua Shuju 中華書局.

Publisher's Note Springer Nature remains neutral with regard to jurisdictional claims in published maps and institutional affiliations. 